\title{
Spillover Effects of Drug Safety Warnings on Health Behavior*
}

\author{
N. Meltem Daysal \\ Tilburg University and IZA \\ Chiara Orsini
University of Venice
}

This Version: February 2012

\begin{abstract}
We examine the impact of new medical information on drug safety on preventive health behavior. We exploit the release of the findings of the Women's Health Initiative Study (WHIS) - the largest randomized controlled trial of women's health which demonstrated in 2002 that long-term Hormone Replacement Therapy increases the risk of heart attacks, stroke, blood clots and breast cancer among healthy postmenopausal women. Because hormone replacement is a therapy exclusive to women, we estimate the spillover effects of the WHIS findings on health behavior by means of a difference-in-differences methodology using men of similar ages as the control group. Using data from the Behavioral Risk Factor Surveillance System for 1998-2007, we find statistically significant small negative spillovers on post-menopausal women's likelihood of having an annual checkup and choice of a healthy diet, as proxied by daily fruit consumption. Our results also indicate that the observed spillover effects of drug safety on health behavior were entirely driven by the less educated. These findings suggest that policies aimed at raising awareness on the safety of medications may have unintended spillover effects on health behavior and that these spillovers may contribute to the existing health disparities by education.
\end{abstract}

Keywords: Spillovers; Preventive Behavior; Health Disparities; Health Production

JEL Classifications: I10, I12, I14, I18

*Daysal: Tilburg University, Warandelaan 2, P.O. Box 90153, 5000 LE Tilburg, The Netherlands (email: meltem.daysal@uvt.nl); Orsini: University of Venice, San Giobbe, Cannaregio 873, 30121 Venice, Italy (email: chrorsini@gmail.com). We thank Bill Evans, Armin Falk, Tamara Konetzka, Peter Kooreman, Willard Manning, Sonia Oreffice, Mircea Trandafir, Eddy van Doorslaer and workshop participants at Erasmus University, Tilburg University and University of Chicago for helpful comments and discussions. The authors bear sole responsibility for the content of this paper. 


\section{Introduction}

In the United States, consumers obtain medical information from a variety of sources, including results of new medical research, direct-to-consumer advertisements (DTCA), Food and Drug Administration (FDA) warnings and announcements, and medical report cards. The production and dissemination of new medical information has substantial costs. National spending on research and development almost doubled during the past decade, from $\$ 23.4$ billions in 1999 to $\$ 45.3$ billions in $2009 .^{1}$ Annual spending on DTCA reached $\$ 4,237$ millions in 2005 (Donohue et al., 2007). Similarly, significant sums of public resources are devoted to the preparation and distribution of medical report cards and FDA announcements and warnings. Consequently, the question of how new medical information impacts consumers has long been of interest to both researchers and policy-makers.

While an extensive body of research shows that individuals change their consumption patterns in response to new drug-related information, the parallel question of how new medical information on drugs impacts a healthy lifestyle and preventive health behavior is largely unexplored. The handful of papers studying the spillover effects of new medical information on health habits have exclusively focused on the marketing and availability of curative products. $^{2}$ In this paper, we add to this literature by investigating how findings of new medical research and the subsequent policy warnings on the safety of preventive drugs impact preventive health behavior. In particular, we examine the response to the findings of the Women's Health Initiative Study (WHIS) which demonstrated in 2002 that long-term Hormone Replacement Therapy (HRT) increases the risk of heart attacks, stroke, blood clots

\footnotetext{
${ }^{1}$ These figures exclude research and development expenditures by drug companies and other manufacturers. Taken from the National Health Expenditure Accounts available at https://www.cms.gov/ NationalHealthExpendData/downloads/tables.pdf, accessed on August 24, 2011.

${ }^{2}$ See Kahn (1999); Iizuka and Jin (2005, forthcoming); Bolton et al. (2006, 2008); Peltzman (2002). Section 2.1 discusses these studies and other related literature.
} 
and breast cancer among healthy post-menopausal women. ${ }^{3}$

We focus on the information provided by the WHIS for a number of reasons. First, there are no real substitutes for the preventive care provided by HRT. The main reason for HRT use among post-menopausal women was to prevent post-menopausal osteoporosis and heart disease, with the latter gaining more emphasis during the 1990s. ${ }^{4}$ The published guidelines for the primary prevention of cardiovascular disease indicate that HRT has been the only pharmacological intervention recommended to reduce the risk of cardiovascular disease. ${ }^{5}$ In its absence, the recommendations for the general public include adoption of healthy lifestyle habits, such as cessation of smoking, regular exercising, weight management and a healthy diet. 6

Second, the WHIS is an ideal source of exogenous variation in drug safety information as it is the largest randomized controlled trial of women's health ever undertaken. ${ }^{7}$ The HRT component, the most debated and closely followed part of the study, was initially scheduled to run until 2005 but was abruptly terminated on July 9, 2002 due to increased health risks among the treated. The story made major headlines across the country. Soon after, in January 2003, FDA announced a formal name change for HRT drugs as "menopausal

\footnotetext{
${ }^{3}$ HRT is a treatment for women that involves taking small doses of female hormones lost due to the aging process. We discuss the history of and the indications for HRT in more detail in section 2.2.

${ }^{4} \mathrm{HRT}$ is also used by middle-aged women as a short-term treatment to alleviate negative symptoms of menopause.

${ }^{5}$ There are alternative drugs that are used in the prevention and treatment of osteoporosis. We show later in the paper that women did not increase their utilization of these alternative medications that could be used as a substitute to HRT drugs.

${ }^{6}$ Other pharmacological therapies such as blood pressure, diabetes and cholesterol medications are recommended only to those with existing risk factors and after an initial period of promotion of healthy lifestyle modifications. Similarly, antiplatelet agents and anticoagulants, $\beta$-blockers and ACE inhibitors are only recommended for individuals with an established cardiovascular disease or after a heart attack. Aspirin was included as a pharmacological intervention in 2002 but only for high-risk individuals. Its indications were expanded to otherwise healthy and not-at-risk individuals in the 2007 guidelines. For more information, see The American Heart Association (1997, 1999, 2002, 2007).

${ }^{7}$ More information on the WHIS is provided in section 2.3 .
} 
hormone therapy", emphasizing its short-term indication in relieving menopausal symptoms, and mandated a boxed warning on the label of HRT drugs informing consumers about the increased risks associated with post-menopausal HRT use.

The WHIS results had a remarkable effect on the use and prescription of HRT drugs among post-menopausal women. Figure 1(a) shows that following the release of the WHIS results, HRT use declined by more than $50 \%$ among women aged 60 years and older. ${ }^{8}$ Similarly, Figure 1(b) shows that the share of office-visits among post-menopausal women that resulted in an HRT prescription declined by almost $43 \%$ from the pre-announcement period of the WHIS results (1998-2002) to the period thereafter (2003-2007).

We examine the effects of the WHIS-findings on the health and health behavior of postmenopausal women (i.e. women aged 60 and more) by means of a difference-in-differences methodology using men of similar ages as the control group because hormone replacement is a therapy exclusive to women. ${ }^{9}$ Using data from the Behavioral Risk Factor Surveillance System (BRFSS) for the period 1998-2007, we find that post-menopausal women experienced statistically significant small reductions in their likelihood of having an annual checkup (1\%) and their choice of a healthy diet (1.3\%), as proxied by daily fruit consumption, when compared to men of similar ages.

The key identifying assumption in our analysis is that men provide the counterfactual of how women would have behaved in the absence of the WHIS findings. Although, this is basically an untestable assumption, we bring suggestive evidence on its plausibility by

\footnotetext{
${ }^{8}$ The medical literature indicates that $75-80 \%$ of women reach menopause by the age of 55 (Mckinlay, 1996; Mckinlay et al., 2008). Since menopausal symptoms can last for a few years after its onset, we include in our sample individuals aged 60 and above as the sample of post-menopausal women. A detailed description of the data sources used to construct these graphs are provided in the Appendix.

${ }^{9}$ In Daysal and Orsini (2011), we show that although the WHIS findings and the subsequent FDA-warnings had no indications on the safety of short-term use of HRT for relieving symptoms of menopause, the use of HRT declined substantially among middle-aged women as well. For that reason, this group of women does not constitute an appropriate control group for the current analysis.
} 
showing that we cannot reject that the evolution of the outcomes in the pre-treatment period among the two groups were statistically identical. We also conduct additional robustness checks, such as examining the possibility of a bias from changes in state-based preventive health policies or peer effects and confirm the robustness of the baseline results.

In the last section of the paper, we examine the heterogeneity in response to the WHIS findings by education. We find that although HRT use was much more prevalent among the more educated, the relative change in HRT use between the pre- and post-announcement of the WHIS findings was similar among the more and less educated post-menopausal women. Our results also indicate that the baseline spillover effects were mainly driven by the lesseducated and imply larger effects in both absolute and relative terms. For example, we find that women with at most a high-school degree were 1.3 percentage points less likely to have an annual checkup during the post-WHIS period as compared to men, which translates into a $1.5 \%$ increase when compared to the mean of the outcome among these women during the pretreatment period. Similarly, the magnitude of the effect on fruit consumption corresponds to a $2.7 \%$ decline when compared to the pre-WHIS mean among less-educated females.

This paper's empirical work is related to several theories of health behavior. According to the theory of risk compensation, people adjust their behavior in response to perceived changes in risk in such a way that keeps the risk level constant. This offsetting behavior has been referred to as the "Peltzman Effect" or "lulling effect" in previous studies. ${ }^{10}$ Empirical evidence on the presence of offsetting behavior is mixed. While some studies found that the effectiveness of the U.S. traffic and product safety regulations were reduced due to increased consumer irresponsibility (e.g., Peltzman (1975), Viscusi (1984) and Viscusi (1985)), other studies on the impact of the Swedish traffic safety regulations or the U.S. diabetic medical

\footnotetext{
${ }^{10}$ Sam Peltzman was the first to lay out the general theory of risk compensation in the field of economics.
} 
breakthroughs did not find any evidence of offsetting behavior (e.g., Lindgren and Stuart (1980) and Kahn (1999)). To the extent that the WHIS findings led to increased perceptions of heart attack risk, the theory of risk compensation would predict associated increases in preventive health behavior. Thus, our results are consistent with the latter set of studies that found no evidence of offsetting behavior. Different from previous studies that exclusively examined the unintended effects of "positive" information, our results also indicate that there may be asymmetric effects of "negative" information: not only did post-menopausal women not decrease risky behavior but low-educated women actually increased unhealthy life habits.

Why do less educated women start acting in riskier ways? According to the expected utility theory, a rational risk averse individual would be willing to sacrifice current consumption in order to have improved health in the future. Individuals may rationally choose to deviate from the optimal outcomes if they have less information on the benefits of healthy behavior. In addition, the traditional health capital models argue that more educated individuals are more likely to adopt preventive health behavior because education improves an individual's ability to make decisions about his or her health. It follows from these theories that less educated individuals adopt risker behavior at a given point in time. This behavioral gap could increase after the announcement of the WHIS results if the process of getting HRT prescriptions acted as an information source for the less educated women on the benefits of healthy behavior. ${ }^{11}$ The typical story we have in mind is one of a low educated post-menopausal woman who goes to her primary physician to renew her HRT prescription and is reminded of the importance of eating healthy due to increased health risks during post-menopause. It is also plausible that during such prescription renewal visits the physician asks the woman to

\footnotetext{
${ }^{11}$ Watkins (2007) notes that a typical prescription for HRT medications covered a two-month supply of pills. This indicates that women on long-term HRT needed to make frequent doctor or pharmacy visits to refill their prescription.
} 
get her annual checkup upon examining her health records. Such arguments can be extended to the availability of health pamphlets at the pharmacies.

In addition, individuals may rationally deviate from the optimal choices predicted by the expected utility theory if they display cognitive dissonance (Akerlof and Dickens, 1982). Cognitive dissonance, in the most basic sense, means that individuals are uncomfortable holding contradicting beliefs. According to psychologists, most situations that lead to cognitive dissonance challenge individuals" perception of themselves as "smart and nice" people. Whenever the individual is faced with a situation where there is a discrepancy between beliefs and behaviors, (s)he must either change the behavior or the belief in order to reduce the psychological discomfort. The abrupt termination of the WHIS and its findings on the preventive power of long-term HRT products may have created conflicting feelings among less educated individuals. In response to these news, they may have changed their perception regarding the trustworthiness of the medical sciences and thus may have decided to ignore all general recommendations on healthy life habits.

Our results are also consistent with behavioral models where time preference plays an important role. The theory of hyperbolic discounting suggests that present-biased preferences could explain the lack of motivation for healthy lifestyle habits that have immediate costs but delayed and uncertain benefits (Laibson, 1997; Loewenstein et al., 2007). Similarly, Ehrlich and Chuma (1990) show that a higher initial health endowment is associated with increases in demand for health investment and Becker and Mulligan (1997) argue that differences in health lead to differences in time preference through reductions in mortality and increases in future utility levels. To the extent that low-educated individuals believed that they have low health endowments, the preventive drug safety information may have induced them to engage in present-biased behavior by reducing their expected lifespan and thus changing 
their time preferences.

Fatalism is another possible explanation for our findings. Fatalism consists in the belief that no matter what a person does, his/her actions can do too little to impact future outcomes (Wu, 2005). A picturesque example is one of the athlete who "throws in the towel" when (s)he thinks that the possibility of winning a competition is low. As discussed in more detail in the next section, HRT was presented to be a miracle drug, effective as a short-term therapy in the treatment of menopausal symptoms as well as a long-term therapy for the prevention of serious diseases related to aging. ${ }^{12}$ If less educated women believed that HRT drugs consisted of an important source of preventive care that enabled them to further adopt healthy life choices, it is entirely possible that the WHIS findings led these women to conclude that healthy lifestyles alone would not be adequate to protect them from cardiovascular disease and thus to "throw in the towel" and give up healthy lifestyles. Fatalistic tendencies are not at all uncommon in determining health preventive behavior. For example, Kremer (1996) shows that an increase in the probability of contracting HIV might lead individuals with a high number of sexual partners to increase sexual activity because they become fatalistic about the probability of contracting the disease.

Finally, our results are consistent with the predictions of the health belief model - one of the most accepted theories in the field of health education. ${ }^{13}$ The original formulation of this theory is much like a cost-benefit calculation. An individual is predicted to adopt preventive behavior the higher the probability of getting a disease that is sufficiently serious in

\footnotetext{
${ }^{12}$ As an illustrative example, consider the $2001 \mathrm{TV}$ commercial for Premarin, the most common HRT drug aired in that year: http://www.youtube.com/watch?v=16LU5F7-gE4. Consider now the 2005 ad for Prempro, the main drug tested during the Women's Health initiative study: http://www.youtube.com/ watch? $\mathrm{v}=\mathrm{xBmDzyJ}$ 3tqw. The are striking differences in the messages of these commercials which are merely four years apart: half of the second commercial is devoted to listing the negative side effects of the drug without any encouragement of adopting healthy habits instead of taking HRT.

${ }^{13}$ For more details, see Glanz et al. (2008).
} 
severity (i.e. "perceived threats"), the higher the effectiveness of the said action in reducing the threat (i.e. "perceived benefits") and the lower the costs of taking that action (i.e. "perceived barriers"). The later formulations of the theory include two additional concepts: "cues to action" that describes situations, such as provision of educational materials and counseling, that can increase an individual's readiness to act and "self-efficacy" that refers to one's confidence in his/her ability to take actions to produce the required outcomes. The concept of cues to action is closely related to our first argument - the process of getting HRT products could be influential for less educated women in remembering the benefits of healthy habits. Previous medical studies provide support for this claim by documenting that advice from health professionals was rated as the most important cue among various domains (McKee, 1994; Jones et al., 2000; Olsen et al., 2010). Self-efficacy, on the other hand, is related to our argument on fatalism. Less educated women could perceive medical products and preventive behavior as complementary goods so the loss of perceived protection by HRT could lead to a reduction in women's confidence to prevent heart disease by solely relying on a healthy life style.

The above discussion suggests that our results are consistent with a broad set of theories both within economics and outside of it. Although data limitations constrain our ability to pinpoint the exact mechanisms leading to the observed spillover effects, we nonetheless believe that our results have important policy implications that pertain directly to the current debate on health care. During the past few decades, health spending has increased dramatically in most developed countries. The United States spent $17.4 \%$ of its gross domestic product on health care in 2009. At the same time, chronic diseases replaced infectious diseases as the most frequent causes of death around the globe. Current estimates indicate that heart disease, cancer and stroke account for two-thirds of all deaths and that behavioral 
factors, such as tobacco use, diet and exercise habits and alcohol consumption are among the leading contributors to mortality (Curry and Fitzgibbon, 2009). As the population ages, the burden of these chronic diseases will also increase. Our results indicate that new medical information on preventive drug safety may have unintended negative effects on healthy life habits possibly contributing to the costs of these diseases. Our findings also have insights for drawing a more complete picture of the value of new medical information and suggest that any cost-benefit analysis on the value of medical information should take these spillovers into account. Finally, our results on the heterogeneity of responses speak to the debate on existing health disparities by education and imply that adoption of unhealthy habits by the less educated following information on harmful effects of drug safety may widen the current health gap.

The remainder of the paper is organized as follows. Section 2 presents a background on the related literature, HRT and WHIS. Section 3 outlines the empirical framework, while section 4 introduces the data. The results are presented in section 5 along with robustness checks and a discussion on heterogeneous effects. Finally, section 6 concludes.

\section{Background}

\subsection{Previous Literature}

There is an extensive body of research that shows that consumers are generally responsive to medical information. Drug sales are found to be related to marketing information, FDA warnings and scientific evidence (Berndt et al., 1995; Azoulay, 2002; Parkinson et al., 2008) and exposure to advertising is shown to increase the probability of quiting smoking (Avery et al., 2007) as well as compliance with the advertised drug therapy (Calfee et al., 2002). 
Similarly, previous literature documents that the quality information provided by plan ratings and report cards has a significant impact on individuals' choice of health plans and health care providers (Dranove et al., 2003; Chernew et al., 2004; Cutler et al., 2004; Dafny and Dranove, 2008).

Past research also shows that the consumption effects of medical information pertaining to specific drugs are not restricted to those drugs only but that there are spillovers to others. Evidence suggests that DTCA on prescription drugs increases the sales of the same-brand over-the-counter medications (Ling et al., 2002) and compliance with drug therapy for all medications (Wosinska, 2005), and that the FDA prescription drug withdrawals lead to reduced utilization of the non-withdrawn drugs within the same therapeutic class (Cawley and Rizzo, 2008).

Despite its potentially important public policy implications, the related question of how new medical information on drugs impacts a healthy lifestyle has received very little attention. Iizuka and Jin (2005) and Iizuka and Jin (forthcoming) use instrumental variable methods and find that DTCA exposure is associated with increased doctor visits but reduced likelihood of engaging in moderate exercise. ${ }^{14}$ Conducting a series of experiments, Bolton et al. (2006) and Bolton et al. (2008) find that marketing curative drugs related to various risky health behavior, such as smoking and having a high-fat diet, increases intentions to engage in risky behavior. Finally, Kahn (1999) and Peltzman (2002) examine the impact of

\footnotetext{
${ }^{14}$ Iizuka and Jin (2005) estimate the impact of DTCA intensity on a given drug class in a given month on the number of doctor visits related to that drug class, controlling for drug class and month effects as well as class-specific time-trends and class-specific seasonality. Iizuka and Jin (forthcoming) estimate linear probability models that relate the likelihood that a given individual from a given MSA and year engages in moderate/vigorous exercise to the intensity of DTCA in that MSA from four specific conditions (diabetes, hypertension, high cholesterol and overweight), observable characteristics, drug-class and year effects. In both cases, they use a given drug companies' DTCA expenditures in unrelated drug classes as an instrument for the measure of DTCA. However, this instrument violates exclusion restrictions if there are common factors that determine how companies target prescription drug advertising.
} 
medical breakthroughs on subsequent preventive health behavior. Kahn (1999) studies the effects of the availability of new diabetic medications on diet and does not find any evidence that access to improved medications led to worse health habits. Peltzman (2002) investigates the impact of the development of antibiotics on mortality and finds that the development increased the mortality risk among age groups and in regions that were most likely to benefit from the innovation. He interprets this as suggestive evidence of offsetting behavior where individuals adopt risky health behaviors in response to the availability of a curative product.

We make several contributions. As described above, previous studies exclusively focused on the effects of marketing and availability of curative products. In contrast, we study responses to the findings of a highly publicized randomized trial and the subsequent FDA warnings. Second, we examine how information on the safety of a preventive drug impacts health behavior, which may differ from the impact of curative products. Third, the marketing and availability of curative products involve the provision of positive information (i.e. that there is a cure available). Our study, on the other hand, investigates consequences of providing information on the harmful effects of HRT, which may differ from the predictions based on studies involving positive information if there are asymmetric responses to positive and negative information. Finally, to our knowledge, our study is the first to use a quasiexperiment when addressing this question and thus improves upon previous studies that may suffer from various endogeneity biases.

\subsection{Hormone Replacement Therapy}

Hormone replacement therapy is a treatment that involves taking small doses of female hormones that the natural aging process takes away. Female hormones (estrogen and progesterone) are produced naturally by the ovaries. As women approach menopause, i.e. their 
final menstrual period, their ovaries shrink and the levels of female hormones start to fluctuate. ${ }^{15}$ During the years immediately before menopause (peri-menopause) and the years that follow (post-menopause), the production of female hormones gradually slows down and eventually stops. Peri-menopausal and menopausal women can experience negative symptoms, such as hot flashes, night sweats, sleep disturbances and vaginal atrophy, as their bodies try to adopt to reduced hormone levels. Although most of these symptoms disappear during post-menopausal years, post-menoapausal women face increased risk for serious health problems, such as heart disease, stroke, and bone loss that can result in osteoporosis and fractures. ${ }^{16}$.

During the early 20th century, when estrogen was first isolated from the urine of pregnant women in 1929 and potent estrogens were subsequently extracted from the urine of pregnant mares in 1939, HRT was mainly intended as a short-term therapy to relieve the negative symptoms of menopause (Watkins, 2007). The idea that HRT could be used as a long-term therapy to improve the health of post-menopausal women emerged during the mid-20th century as scientists put forward hypothesis linking reduced female hormones to the onset of osteoporosis, cardiovascular disease and dementia, and drew analogies between estrogen deficiency after menopause to insulin deficiency in diabetes (Watkins, 2007). Watkins (2007) notes that the April 1984 osteoporosis treatment consensus group of the National Institutes of Health recommended estrogen therapy without specific limitations to its duration of use. Soon after that, Food and Drug Administration added in April 1986 the treatment of postmenopausal osteoporosis to the indications of $\mathrm{HRT}^{17}$ and recommended in a special two-day

\footnotetext{
${ }^{15} \mathrm{~A}$ woman is classified to be in menopause if she did not have any menstrual periods for 12 consecutive months without being ill, pregnant or breast-feeding.

${ }^{16}$ For more information on the menopause transition, see The North American Menopause Society (2006); National Heart, Lung and Blood Institute (2005).

${ }^{17}$ Food and Drug Administration (1986), "Oral Estrogens for Postmenopausal Osteoporosis; Drug Efficacy Study Implementation; Reevaluation," Federal Register 51, 12568-12570.
} 
workshop that any women over the age of 50 should be seen as a candidate for long-term HRT (Watkins, 2007). The American College of Physicians agreed with these recommendations stating in their 1992 guidelines for counseling post-menopausal women that "all women, regardless of race, should consider preventive hormone therapy" (American College of Physicans, 1992, p. 1038).

The available statistics from these periods reflect the increased popularity of HRT as a long-term preventive medication. The number of oral estrogen prescriptions increased from 13.6 millions in 1982 to 20.1 millions in 1987 to 36.5 millions in 1992 (Wysowski et al., 1995). Furthermore, the share of oral estrogens prescribed to post-menopausal women aged 60 and above increased from 19 percent in 1979 to 25 percent in 1986 to 30 percent in 1992 (Hemminki et al., 1988; Wysowski et al., 1995). ${ }^{18}$ Premarin, the conjugated estrogen by Wyeth-Ayerst Laboratories, became the most frequently prescribed drug in 1992 and remained in the top two most prescribed drugs in the United States for every year during the 1990s (Watkins, 2007).

Given the widespread HRT use and the aging of the American population, the 1990s began with an even more pronounced need for a reliable study examining the effects of longterm HRT on the health of post-menopausal women. It is then not surprising that out of this need the National Institutes of Health established in September 1990 the Office of Research on Women's Health, which would soon found the Women's Health Initiative Study.

\subsection{Women's Health Initiative Study}

The Women's Health Initiative Study was launched in April 1991 with the aim of evaluating the effectiveness of several strategies for preventing major diseases and promoting good health

\footnotetext{
${ }^{18}$ The statistic for 1992 reflects the share of Premarin prescriptions dispensed to women aged 60 and above. Premarin was the most commonly used oral estrogen in 1992 (Wysowski et al., 1995).
} 
among post-menopausal women. ${ }^{19}$ The study, sponsored by the National Heart, Lung, and Blood Institute, consisted of three components: a clinical trial, an observational study and a community prevention study. The clinical trial further included three study components. The Hormone Therapy component aimed to examine the preventive effects of HRT on heart disease and osteoporosis, keeping in mind the potential risks for breast cancer. It included separate trials for examining the effects of estrogen with progestine among women with uterus and estrogen alone among women without uterus. ${ }^{20}$ The focus of the Dietary Modification component was the impact of a low-fat, high fruit, vegetable and grain diet on the prevention of breast cancer, colorectal cancer and heart disease. Finally, the Calcium/Vitamin D study investigated the role of these supplements on the prevention of osteoporosis, fractures and colorectal cancer. The observational study analyzed the association between lifestyle, health and risk factors by collecting data on medical history and health habits and looking for biological markers of specific diseases. The community prevention study sought to find effective community-based prevention strategies to promote healthy behaviors, especially among socioeconomically disadvantaged groups.

Between October 1993 and October 1998, the study recruited more than 160,000 participants, of which more than 68,000 were assigned to the clinical trials and nearly 28,000 women were assigned to the HRT trials. Although the project was initially expected to cost $\$ 625$ million, the final cost was much higher. To this day, the WHIS continues to be the

\footnotetext{
${ }^{19}$ For more information on the WHIS, visit the study's webpage by the National Heart, Lung, and Blood Institute at http://www.nhlbi.nih.gov/whi/index.html and see the references and links therein.

${ }^{20}$ The combined estrogen-progestin trial participants were randomly assigned to a daily dose of 0.625 milligrams of conjugated estrogen plus 2.5 milligrams of medroxyprogesterone acete (Prempro by the WyethAyerst Pharmaceuticals) or a placebo. Similarly, participants of the estrogen-only trial were randomly assigned to a daily dose of 0.625 milligrams of conjugated estrogen (Premarin by the Wyeth-Ayerst Pharmaceuticals) or a placebo. Prempro and Premarin were chosen because they were the most commonly prescribed forms of HRT. Furthermore, their benefits were examined in previous observational studies (National Heart, Lung and Blood Institute, 2005).
} 
largest randomized controlled trial of women's health ever undertaken.

During the recruiting years of the WHIS, HRT kept gaining its popularity as a preventive medicine. The number of HRT prescriptions kept rising throughout the 1990s, reaching 90 million in 1999 (Hersh et al., 2004). More importantly, HRT gained acceptance for indications for which it was not FDA-approved, most notably for prevention of heart disease. In a national survey conducted by the National Heart, Lung, and Blood Institute, Rossouw (1996) found that $66 \%$ of the surveyed cardiologists, internists, family doctors and general practitioners prescribed HRT for prevention of coronary heart disease. Similarly, surveys of providers within several health maintenance organizations from this period show that over $95 \%$ of providers believed that the greatest benefit of HRT was in the prevention of cardiovascular conditions (Rolnick et al., 1999) and that physicians who were convinced of the benefits of HRT in preventiving heart disease were more likely to prescribe it (Newton et al., 2001).

The HRT component of the WHIS was scheduled to run until 2005. However, the clinical trial on combined estrogen-progestin hormones was abruptly terminated on July 9, 2002 in the interest of safety, after an average follow up of 5.2 years. ${ }^{21}$ The results of the trial indicated that the combined estrogen-progestin use would lead to 7 more heart attacks, 8 more strokes, 18 more blood clots and 8 more breast cancers annually per 10,000 postmenopausal women. They also indicated that the combined HRT use would result in 5 less hip fractures and 6 less colon cancers per year per 10,000 post-menopausal women (Writing Group for the Womens Health Initiative Investigators, 2002). Although the scientific results were officially published on July 17,2002 , the study was released to the public early on July 9, 2002 because of the importance of the findings.

\footnotetext{
${ }^{21}$ U.S. Department of Health and Human Services (2002), "NHLBI Stops Trial of Estrogen Plus Progestin Due to Increased Breast Cancer Risk, Lack of Overall Benefit," NIH News Release, 9 July 2002.
} 
The WHIS did not stop the clinical trial on the use of estrogen-alone among women without a uterus but tides turned clearly against long-term HRT after July 2002. Not surprisingly, the story made front pages in all major newspapers and was covered in broadcasts on national television. ${ }^{22}$ In the wake of the WHIS news, Wyeth's stock prices fell by more than 24 percent. $^{23}$. The news were followed by statements from various policy makers and research groups. Most of these statements focused on the results pertaining to the effects of long-term HRT use on coronary heart disease. FDA released a statement in August 2002 stating that "[t]he increased risks of breast cancer and thromboembolic disease associated with estrogen and combination estrogen/progestin had previously been known or suspected. The increased risk of cardiovascular disease, including heart attack and stroke, in healthy women, is new information" (Food and Drug Administration, 2002, p.1). ${ }^{24}$ The National Heart, Lung, and Blood Institute announced September as the "menopause awareness month" and published a booklet describing the WHIS findings (National Heart, Lung and Blood Institute, 2005). Similarly, the North American Menopause Society concluded in its October 2002 advisory panel that estrogen-progestin should not be used for the prevention of heart disease (Watkins, 2007).

\footnotetext{
${ }^{22}$ Guthrie, Patricia (2002), "Study Halts Hormone Therapy," Pittsburgh Post-Gazette, 9 July 2002. Kalota, Gina (2002), "Study is Halted Over Rise Seen in Cancer Risk," NY Times, 9 July 2002. Rubin, Rita (2002), "U.S. Halts Study on Hormone Therapy," USA Today, 9 July 2002.

${ }^{23}$ Peterson, Melody (2002), "Wyeth-Stock Falls 24\% After Reported," Ny Times, 10 July 2002.

${ }^{24}$ The potential harmful effects of HRT on heart disease was first reported in August 1998 by the Heart and Estrogen/Progestin Replacement Study (HERS). HERS was a randomized trial on the effects of combined HRT medications on the prevention of a secondary heart attack or other coronary event. The study consisted of 2,763 women between the ages of 44 to 67 who already had heart disease. After 4 years of follow-up, it found that HRT was not effective in preventing a secondary coronary event. Furthermore, it increased the risk of having a blood clot (Hulley et al., 1998). However, these results did not receive almost any media attention. Watkins (2007) notes that none of the newspapers covered the story on their front-page. For example, she writes that the NY Times reported the HERS results only on page 20. Although the findings were reported on some channels, there were no follow-ups. As we showed in Figure 1, the fact that HRT use kept rising even after the HERS results is consistent with the observation that these results were received with skepticism and did not impact the perceptions of patients or physicians pertaining to the preventive effects of long-term HRT.
} 
The final verdict on the preventive role of long-term HRT came in January 2003 as FDA announced a formal name change for HRT drugs as "menopausal hormone therapy" and mandated a boxed warning on the label of HRT drugs about the increased risk of heart attacks, stroke and blood clots. ${ }^{25}$ Since then, FDA recommends HRT use for relief of "moderate to severe vasomotor symptoms associated with menopause, treatment of vulvar and vaginal atrophy and prevention of postmenopausal osteoporosis". FDA has also been emphasizing that HRT products should be used at the lowest dose and for the shortest necessary duration.

In the years that followed, news for HRT went from bad to worse. The WHIS stopped its estrogen-only clinical trial in March 2004, one year before its scheduled end date, because even after a 7 year follow-up there was no evidence of an effect on heart disease but there was evidence of an increased risk of stroke. ${ }^{26}$ Related studies also found that long-term HRT use, either in combined estrogen-progestin or estrogen-only form, was associated with an increased risk of dementia and reduced cognitive functioning (Shumaker et al., 2003; Rapp et al., 2003; Shumaker et al., 2004; Espeland et al., 2004). That said, none of these news had the same marked effect as the news of July 2002.

In summary, the WHIS was conducted at a time when HRT was widely used and was perceived to be a miracle drug, effective as a short-term therapy in the treatment of menopausal symptoms as well as a long-term therapy for the prevention of serious diseases related to aging, most notably for the prevention of cardiovascular disease. The abrupt termination of the combined HRT trial, the highly publicized nature of the findings, the strong response of policy makers to the news, and the size of the potentially affected group makes this an

\footnotetext{
${ }^{25}$ Food and Drug Administration (2003), "FDA Approves Prescribing Information for Postmenopausal Hormone Therapies," FDA Letter to Wyeth Pharmaceuticals, 6 January 2003.

${ }^{26}$ U.S. Department of Health and Human Services (2004), "NIH Asks Participants in Women's Health Initiative Estrogen-Alone Study to Stop Study Pills, Begin Follow-Up Phase," NIH, 2 March 2004.
} 
ideal quasi-experiment when examining how medical information on drugs affects a healthy lifestyle.

\section{Empirical Strategy}

We use a difference-in-differences approach to estimate the effects of the medical information provided by the WHIS on the health and health behavior of post-menopausal women. ${ }^{27}$ Because hormone replacement is a therapy exclusive to women, we identify the effects by comparing the change in outcomes between the pre- and post-announcement periods of the WHIS results among near elderly and elderly women ("treated group") with the change among men of similar ages ("control group"). The key equation of interest can be described as:

$$
Y_{i t}=\beta_{0}+\beta_{1} \text { Post }_{t}+\beta_{2} \text { Female }_{i}+\beta_{3} \text { Post }_{t} * \text { Female }_{i}+\epsilon_{i t}
$$

where the unit of observation is individual $i$ in year $t . Y_{i t}$ is an outcome variable capturing self-reported health or health behavior, Post $t_{t}$ is a dummy variable indicating the period after

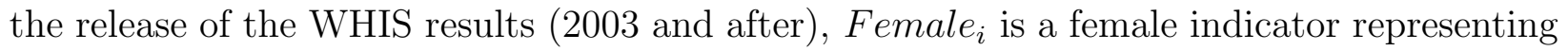
the treatment group and $\epsilon_{i t}$ is an idiosyncratic error term. The coefficient on Post $_{t} *$ Female $_{i}$ measures whether there is a differential change in health or health behavior between the preand post-periods in the treatment group relative to the control group.

We enrich this basic specification in different ways. We add a set of control variables describing the observable characteristics of each individual $\left(X_{i t}\right)$. We replace the post period

\footnotetext{
${ }^{27}$ One point worth noting is the reason for why we do not examine the impact of HRT use on preventive health behavior and instrument for HRT use with the WHIS findings. The key identification assumption required in this case is the instrument excludability: that the WHIS findings impact health behavior only through changes in HRT use. However, it is possible that the WHIS findings impacted preventive health behavior by simply reminding women of various health risks associated with post-menopause, thereby violating the exclusion restriction.
} 
dummy variable with a full set of survey month and year indicators to allow for a more flexible time series pattern when controlling for overall changes in the outcome. Finally, we include a set of state dummy variables to correct for time-invariant or slowly changing state specific factors that might impact the health or health behavior of residents.

Our key identifying assumption is that men provide the counterfactual of how women would have behaved in the absence of the release of the WHIS-findings. Although, this is basically an untestable assumption, we can test its plausibility by checking the evolution of the outcomes in the pre-treatment period among the two groups. In particular, we restrict our sample to 1998-2002 and estimate the following equation:

$$
Y_{i t}=\alpha_{0}+\alpha_{1} X_{i t}+\alpha_{2} \text { Female }_{i}+\sum_{t=1999}^{2002} \alpha_{3, t} \text { Year }_{t}+\sum_{t=1999}^{2002} \alpha_{4, t} \text { Year }_{t} * \text { Female }_{i}+c_{s}+\nu_{i t}
$$

Testing the joint significance of the coefficients of the interaction terms of year and female indicator $\left(\right.$ Year $_{t} *$ Female $\left._{i}\right)$ would provide information on the equality of the pre-treatment trends in outcomes between men and women.

Finally, all specifications allow for the error term to be auto-correlated within states and estimate robust standard errors clustered at the state level (Bertrand et al., 2004).

\section{Data}

To assess the effects of the WHIS findings on the health and health behavior of postmenopausal women, we use data from the Behavioral Risk Factor Surveillance System (BRFSS) for the period 1998-2007. The BRFSS is a nationally representative telephone survey designed to provide information on risky behavior and preventive health practices of the civilian, noninstitutionalized adult population. The survey is administered by individ- 
ual states and the data are edited and processed by the Centers for Disease Control and Prevention (CDC).

The BRFSS survey is made up of three parts. The core component includes a set of questions that are asked by all states. However, these questions can be asked in every year (the fixed-core questions) or in alternating years (the rotating-core questions). Every year, a set of questions pertaining to the latest health issues are also added to the core component (the emerging-core questions). These questions are evaluated in the following year to determine whether they will be mainstreamed into the fixed or alternating cores in future surveys. In addition to the core questionnaire, states can also administer questionnaires on specific topics supported by the CDC (the optional modules component) or develop and add their own questions (stated added questions component).

The BRFSS is an excellent dataset for the purposes of our research because it is a very large annual survey including rich information on self-reported health and health habits of adults as well as basic demographic data. Other individual surveys that cover similar information are either not as detailed as the BRFSS or suffer from much smaller sample sizes. For example, the Current Population Survey has detailed demographic data, as well as information on self-reported health status, but it has no information on health habits. The National Health Interview Survey includes data on a range of health and health behavior but it has much smaller sample sizes and the public-use data files do not contain state identifiers. Controlling for state and state-year effects is particularly important in this context because many states implemented welfare reforms during the 1990s and this could have potentially impacted the health behavior of individuals (Blank, 2002; Bitler et al., 2005).

In the empirical analysis, we focus on a set of outcome variables concerning health status and preventive health habits. In particular, our outcomes include an indicator for fair or poor 
self-reported health status, for having a checkup or cholesterol check in the last year, and for being a current smoker. We also examine effects on the choice of healthy diet, as proxied by the number of daily fruit servings. We focus on these outcome variables because smoking, having high blood cholesterol and a diet low in vegetables and fruits are well established risk factors for health conditions, such as heart disease and osteoporosis - conditions for which women are at increased risk after menopause and the leading conditions for which HRT was commonly used as a preventive medicine. Leading medical information sources on women's health advocate smoking cessation, controlling cholesterol and improving nutrition and diet as essential ingredients for maintaining a healthy lifestyle and as viable alternatives to postmenopausal hormone therapy. ${ }^{28}$

In our regressions, we also control for a set of observable characteristics of individuals (denoted by $X_{i t}$ in section 3). These include dummy variables for age (individual dummies for ages $60-69$, and indicators for intervals of 70-74, 75-79 and 80 and above), race (nonHispanic white, non-Hispanic black, non-Hispanic other, Hispanic), marital status (married, single, never married), education (less than high school, high school or GED, some college, college and more), annual household income (less than $\$ 20,000$, [\$20,000-\$25,000), [\$25,000$\$ 35,000)$, [\$35,000-\$50,000), $\$ 50,000$ and more), and current insurance status. ${ }^{29}$

Our analysis sample consists of individuals in the post-menopausal ages. The medical

\footnotetext{
${ }^{28}$ See for example, National Heart, Lung and Blood Institute (2005) and its webpage at http:// www.nhlbi.nih.gov/whi/whi_faq.htm, Food and Drug Administration (2009) or The North American Menopause Society (2006).

${ }^{29}$ One concern is if women get health insurance to be able to afford HRT products. If this is the case, then comparing changes in health behavior among women and men by insurance status would lead to a selection bias in the estimated coefficient of the Post $_{t} *$ Female $_{i}$ interaction term. This type of bias is unlikely in our case since the elderly have almost universal insurance coverage through Medicare. However, in order to shed more light on this issue, we also estimated specifications excluding insurance status as well as models where we used insurance status as the outcome variable. Our analysis confirmed that there was no differential change in the health insurance coverage of women relative men between the pre- and post-announcement of the WHIS findings (the estimated coefficient on the interaction term was $0.000(\mathrm{se}=0.002)$ ).
} 
literature indicates that $75-80 \%$ of women reach menopause by the age of 55 (Mckinlay, 1996; Mckinlay et al., 2008). Since menopausal symptoms can last for a few years after its onset, we include in our sample individuals aged 60 and above. The size of the analysis sample changes depending on the outcome variable examined. All of our outcomes are included in the core component of the BRFSS and thus are administered by all states. However, only self-reported health status and smoking indicators were part of the fixed-core questions and were asked in each year between 1998 and 2007. Questions on annual cholesterol check and daily fruit servings were administered as rotating-core questions. ${ }^{30}$ Finally, the question on annual checkups was administered for the years 1998-2000 and 2005-2007. This leaves us with a sample of 334,671-617,396 observations, depending the outcome studied.

\subsection{Descriptive Statistics}

In this section, we first present evidence on the impact of the WHIS results on the use of alternative osteoporosis drugs among post-menopausal women. ${ }^{31}$ Figure 2 presents trends in the utilization of alternative osteoporosis medications separately for women and men aged 60 and above. ${ }^{32}$ Figure 2(a) shows the fraction of individuals in the Medical Expenditure Panel Survey that reported purchasing at least one alternative osteoporosis drug in that year. The graphs shows that there is no spike in drug use among women (or men) during the post-WHIS period relative to the years before. Figure 2(b) uses data from the National Ambulatory Medical Care Survey and plots the percentage of office-based visits where at

\footnotetext{
${ }^{30}$ The cholesterol check question was asked in odd-numbered years. The question on daily fruit servings was asked in even-numbered years between 1998-2002 and in odd-numbered years between 2003-2007.

${ }^{31} \mathrm{~A}$ detailed description of the alternative osteoporosis medications and data sources used to construct the graphs are provided in the Appendix.

${ }^{32}$ Although Zoledronic Acid was approved by the FDA in the prevention and treatment of osteoporosis in 2007, it existed in the drug market before then. In order to take into account the possibility that it may have been used off-label in the years prior to 2007, we also conducted our analysis by including Zoledronic Acid in each year it was on the market. Our results are virtually the same.
} 
least one alternative osteoporosis medication was prescribed. The graph shows that there was no differential increase in the prescription of these medications to women, as compared to men. To the contrary, the percent changes in drug prescriptions among men and women are remarkably similar during the post-period, implying an even more stable female to male prescription ratio when compared to the pre-2003 period. These graphs confirm that women did not have alternative preventive medications that could be used as a substitute to HRT drugs.

Tables 1 and 2 provide the means and standard deviations of our outcome and control variables from BRFSS. In Table 1, we present summary statistics for the full sample and separately for women and men, as well as for sub-periods determined according to the release of the WHIS findings. These figures provide some preliminary, descriptive evidence on the effects of the medical information provided by the WHIS findings on health and health related behavior. The table suggests that women did not behave in healthier ways or adopt more preventive checks during the post-period as compared to men. In particular, with respect to preventive care, the fraction of women who reported having an annual checkup within the last year declined by almost $2.5 \%$ from $86 \%$ in pre-period to $84.2 \%$ in the post-period, whereas the corresponding change for men was around $1.2 \%$. The figures also show that the fraction of current smokers declined by a smaller amount for females (8.3\%) than males (10.4\%), and the average number of daily fruit servings declined more among women (6.4\%) than among men $(5.5 \%)$. Despite these differences in health behavior, the descriptive statistics do not show a differential change in self-reported health status among men and women. In the next section, we provide our estimation results and check if the observed differences documented here persist after controlling for other potentially confounding factors. 


\section{$5 \quad$ Econometric Results}

\subsection{Baseline Results}

Table 3 presents the main results. Each row provides results on a separate outcome variable. The first column provides means of the outcome variables among women during the pretreatment period. Columns (2)-(3) provide the effects of the medical information provided by the WHIS on health and health related behavior. In order to gauge the importance of time-varying characteristics, we first estimate in column (2) a simple difference-in-differences model described by equation (1), and then in column (3) models from our full specification. Regressions are weighted by the final weights provided in the BRFSS. Robust standard errors clustered at the state level are shown in parenthesis below coefficients.

The results consistently show that women started acting in unhealthier ways relative to men during the post-WHIS period when they were less likely to take HRT for preventive purposes. The estimates are statistically significant for having an annual checkup and the number of daily fruit servings. For example, the estimate on annual checkups in column (3) suggests that women were 0.7 percentage points less likely to have an annual checkup during the post-WHIS period as compared to men, a roughly $1 \%$ decline when compared to the mean of the outcome among women during the pre-treatment period. Similarly, the results on fruit consumption indicate that women on average consumed 0.023 less servings of fruit per day during the post-WHIS period as compared to men, a $1.3 \%$ decline at the pre-period mean of the outcome among women. Contrary to outcomes on health behavior, the regression results do not provide any evidence of an effect on self-reported health. ${ }^{33}$

\footnotetext{
${ }^{33}$ If we assume that these behavioral changes come entirely from HRT users, we can do a back-of-the envelope calculation for the upper-bound of the estimates by scaling them with 0.22 (i.e. the average fraction of HRT users among post-menopausal women during the pre-period in the MEPS). This implies a 3.2 percentage-point reduction in the probability of having an annual checkup, and a 0.1 reduction in the
} 
As we described before, the key identifying assumption in difference-in-differences models is that the control group provides the counterfactual of what would have happened in the treated group in the absence of the treatment. Although, this is basically an untestable assumption, we can shed some light on it by checking the evolution of the outcomes in the pre-treatment period among the two groups. In order to do so, we run equation 2 described in section 3. The p-values corresponding to the null hypothesis testing the significance of the interaction variables (i.e. equality of the pre-treatment trends in outcomes among men and women) are provided in column (3) in square brackets. It is reassuring that for none of our selected outcomes we reject the equality of the pre-treatment trends in outcomes among men and women.

\subsection{Robustness Checks}

In this section, we provide additional analysis checking the robustness of the baseline estimates. Table 4 presents the results. The first column reproduces our baseline estimates from the specification including all controls for reference (compare to column (3) in Table 3). The second column checks the appropriateness of using a linear model for binary outcomes. The average marginal effects from a logit specification, reported in this column, confirm the previous baseline estimates produced by the linear specification. The results are qualitatively similar and quantitatively close to those provided by the baseline specification. For the remainder of the checks, we therefore report results from linear models for the sake of brevity.

The third column attempts to account for a potential bias arising from changes in state based preventive health policies. The 1990s and 2000s witnessed an increased awareness number of daily fruit servings among post-menopausal women during the post-2002 period as compared to men. 
in the importance of access to preventive health services. The U.S. Department of Health and Human Services released on September 6, 1990 a report detailing national public health goals and objectives for the decade. The report (Healthy People 2000: National Health Promotion and Disease Prevention Objectives) was followed by another initiative (Healthy People 2010: Objectives for Improving Health), released on January 25, 2000, updating the goals for the year 2010. Both of these reports placed great emphasis on the role of preventive services. For example, of the 22 focus areas in the earlier report, 21 were related to health promotion, health protection, and preventive services. Similarly, the 28 focus areas of the Healthy People 2010 included among others, promotion of health through better diet and nutrition, fitness and physical activity as well as reducing exposure to secondhand smoke and diseases related to tobacco use. The development and implementation of these goals represented a concerted effort at the national, state and community level.

To the extent that the implementation of the programs associated with these initiatives varied across states, this could contaminate our estimates. To examine this issue, we add state-specific year effects to our baseline estimates. This should capture any effect that is common to all individuals within a unique state-year cell. The results provided in column (3) are virtually the same as those in the baseline model.

In the last column of Table 4, we turn to the possibility of a bias in our estimates due to peer effects. Previous research indicates that social influences are important in shaping the health behavior of teenagers, including alcohol consumption (Kremer and Levy, 2008), smoking (Powell et al., 2005; Gaviria and Raphael, 2001), substance abuse (Lundborg, 2006; Clark and Loheac, 2007) and sexual initiation (Fletcher, 2007). There is also evidence on the importance of network effects in facilitating participation in welfare programs (Bertrand et al., 2000), utilization of health services (Deri, 2005) as well as in retirement and saving 
decisions (Duflo and Saez, 2002, 2003; Brown and Laschever, 2011). Most related to our context is the finding from the Health and Retirement Study that social interactions are an important determinant of the health insurance choices of the elderly (Beiseitov et al., 2004).

If peer effects lead to spillovers from women to the rest of their communities, then men might not constitute a good control group and our baseline estimates might be biased. Since such a scenario would indicate that there are potentially treated individuals among our control group, it is reassuring that such a bias would imply that our results represent lower bounds. In order to explore this issue in more detail, we bring suggestive evidence by examining effects on the sub-sample of single individuals. Research on social networks and health suggest that peer effects should get weaker as the social distance between the individuals increases (Smith and Christakis, 2008). Among the elderly, the arguably most important peer effect is through spousal interactions. ${ }^{34}$ For that reason, a potential bias from peer effects should be minimal among the sample of single individuals. Estimates, reported in column (4), confirm the sign of our original findings for all outcomes, except for annual checkups where the standard errors associated with the point estimates are too large to allow us to draw any inference.

\subsection{Heterogeneous Effects}

Economic theory suggests that education may have an important impact on the health behavior of individuals. For example, Grossman (1972) and Schultz (1975) argue that education may improve an individual's health production function and increase allocative efficiency

\footnotetext{
${ }^{34}$ Previous studies find spousal spillover effects in alcohol consumption (Leonard and Mudar, 2004), use of a range of preventive care indicators (Falba and Sindelar, 2008) and mental health (Fletcher, 2009). There is also a large body of research that documents increased mortality rates among recently widowed individuals, often referred to as the "bereavement effect". For a review of this literature, see Smith and Christakis (2008) and Espinosa and Evans (2008).
} 
through enhanced learning and ability to process information. In this section, we examine the heterogeneity in response to the WHIS findings by education. Figure 3 shows the percentage of post-menopausal women in MEPS who reported using HRT separately for those with at most a high school degree (the solid line) and those with at least some college education (the dashed line). ${ }^{35}$ According to the graph, although HRT use was much more prevalent among the more educated, the relative change in HRT use between the pre- and post-announcement of the WHIS findings was slightly larger among the less educated postmenopausal women. The average fraction of less-educated post-menopausal women who reported using an HRT product declined from 20 percentage points during the pre-period (1998-2002) to 8 percentage points during the post-period (2003-207). Similarly, among the more-educated women, HRT users declined from an average of 28 percentage points during 1998-2002 to an average of 13 percentage points during 2003-2007.

In Table 5, we examine the heterogeneity in health behavior of individuals with different levels of education. The first column provides our baseline estimates from the full sample for reference (compare to column (3) in Table 3). The second column provides estimates on the sample of individuals with a high school degree or less, while the last column reports estimates for those with at least some college education. The pre-period mean of the outcome among the treatment group (i.e. women) is reported in square brackets below the standard error.

The spillover effects among the low-educated individuals, reported in column (2), are statistically significant for the same set of outcome variables but they are larger than the baseline results in both absolute and relative terms. For example, the estimate on annual checkups in row (2) suggests that less-educated women were 1.3 percentage points less likely

\footnotetext{
${ }^{35}$ Unfortunately, the NAMCS does not include information on the educational attainment of the patient observed in the office-visit.
} 
to have annual checkup during the post-WHIS period as compared to men, which translates into a $1.5 \%$ decline when compared to the mean of the outcome among these women during the pre-treatment period. Similarly, the magnitude of the effect on fruit consumption corresponds to a $2.7 \%$ decline when compared to the pre-WHIS mean among females with at most a high-school degree. The results from the sample of more educated women reported in column (3), on the other hand, are statistically insignificant for all outcomes and much smaller in magnitude. Overall, these results indicate that the baseline estimates, where we found an increase in risky behavior among women during the post-WHIS era as compared to men, were mainly driven by the less-educated.

\section{Conclusion}

In this paper, we examine the response to the medical findings from the WHIS and the subsequent public policy actions that documented the harmful health effects of long-term HRT. We first show that following the release of the WHIS findings, HRT use and prescriptions declined substantially among women aged 60 years and older without corresponding changes in the utilization of alternative medications that had similar indications as HRT. We then implement difference-in-differences models using men of similar ages as the control group to examine potential spillover effects of these new medical information on health and health behavior. Our results point to statistically significant small negative spillovers on post-menopausal women's likelihood of having an annual checkup and choice of a healthy diet, as proxied by daily fruit consumption.

In the final section of the paper, we examine the heterogeneity in the response to the WHIS by educational attainment. Our results indicate that the relative change in the utilization of HRT was similar among low and high-educated post-menopausal women but the 
spillover effects on preventive behavior were entirely driven by those with a high school degree or less.

As the costs of producing and disseminating new medical information rises, understanding how consumers may respond to these information becomes even more important. Taken together, our results suggest that policies aimed at raising awareness on the safety of medications may have unintended spillover effects on health behavior that reduce the net value of the new medical information. Our analysis on the heterogeneity of the responses further indicate that these spillovers may contribute to the existing health disparities by education.

\section{References}

Akerlof, George A., and William T. Dickens (1982), "The Economic Consequences of Cognitive Dissonance," American Economic Review 72, 307-319.

American College of Physicans (1992), "Guidelines for Counseling Postmenopausal Women about Preventive Hormone Therapy," Annals of Internal Medicine 117, 1038-1041.

Avery, Rosemary, Donald Kenkel, Dean R. Lillard, and Alan Mathios (2007), "Private Profits and Public Health: Does Advertising of Smoking Cessation Products Encourage Smokers to Quit?" The Journal of Political Economy 115, 447-481.

Azoulay, Pierre (2002), "Do pharmaceutical sales respond to scientific evidence?" Journal of Economics and Management Strategy 11, 551-594.

Becker, Gary S., and Casey B. Mulligan (1997), "The Endogenous Determination of Time Preference," The Quarterly Journal of Economics 112, 729-758.

Beiseitov, Eldar, Jeffrey D. Kubik, and John R. Moran (2004), "Social Interactions and the Health Insurance Choices of the Elderly: Evidence from the Health and Retirement Study," Center for Policy Research Working Paper No. 105.

Berndt, Ernst R., Linda Bui, David R. Reiley, and Glen L. Urban (1995), "Information, Marketing, and Pricing in the U.S. Antiulcer Drug Market," The American Economic Review 85, 100-105.

Bertrand, Marianne, Esther Dufflo, and Sendhil Mullainathan (2004), "How much should we trust difference in differences estimates?" Quarterly Journal of Economics 119, 249-275. 
Bertrand, Marianne, Erzo F. P. Luttmer, and Sendhil Mullainathan (2000), "Network Effects and Welfare Cultures," The Quarterly Journal of Economics 115, 1019-1055.

Bitler, Marianne P., Jonah B. Gelbach, and Hilary W. Hoynes (2005), "Welfare Reform and Health," The Journal of Human Resources 40, 309-334.

Blank, M. Rebecca (2002), "Evaluating Welfare Reform in the United States," Journal of Economic LIterature 40, 1105 - 1166.

Bolton, Lisa E., Joel B. Cohen, and Paul N. Bloom (2006), "Does Marketing Products as Remedies Create "Get Out of Jail Free Cards"?" Journal of Consumer Research 33, $71-81$.

Bolton, Lisa E., Americus Reed II, Kevin G. Volpp, and Katrina Armstrong (2008), "How Does Drug and Supplement Marketing Affect a Healthy Lifestyle?" Journal of Consumer Research 34, 713-726.

Brown, Kristine, and Ron Laschever (2011), "When Theyre Sixty-Four: Peer Effects and the Timing of Retirement," Working Paper.

Calfee, John E., Clifford Winston, and Randolph Stempski (2002), "Direct-to-consumer advertising and the demand for cholesterol-reducing drugs," Journal of Law and Economics 45, 673-690.

Cawley, John, and John A. Rizzo (2008), "Spillover Effects of Prescription Drug Withdrawals," Advances in Health Economics and Health Services Research 19, 119-143.

Chernew, Michael, Gautam Gowrisankaran, and Dennis P. Scanlon (2004), "Learning and the value of information: Evidence from health plan report cards," Journal of Econometrics $144,156-174$.

Clark, Andrew E., and Youenn Loheac (2007), "'It wasnt me, it was them!" Social influence in risky behavior by adolescents," Journal of Health Economics 26, 763-784.

Curry, Susan J., and Marian L. Fitzgibbon (2009), "Theories of Prevention," in Sally A. Shumaker, Judith K. Ockene, and Kristin A. Riekert, eds., The Handbook of Health Behavior Change, Springer Publishing Company.

Cutler, David M., Robert S. Huckman, and Mary Beth Landrum (2004), "The Role of Information in Medical Markets: An Analysis of Publicly Reported Outcomes in Cardiac Surgery," American Economic Review 94, 342-346.

Dafny, Leemore, and David Dranove (2008), "Do report cards tell consumers anything they dont already know? The case of Medicare HMOs," RAND Journal of Economics 39, $790-821$. 
Daysal, N. Meltem, and Chiara Orsini (2011), "The Miracle Drugs: Hormone Replacement Therapy and Labor Market Behavior of Middle Aged Women," Working Paper.

Deri, Catherine (2005), "Social Networks and Health Service Utilization," Journal of Health Economics 24, 10761107.

Donohue, Julie M., Marisa Cevasco, and Meredith B. Rosenthal (2007), "A Decade of Directto-Consumer Advertising of Prescription Drugs," The New England Journal of Medicine $357,673-681$.

Dranove, David, Daniel Kessler, Mark McClellan, and Mark Satterthwaite (2003), "Is More Information Better? The Effects of Report Cards on Health Care Providers," The Journal of Political Economy 111, 555-588.

Duflo, Esther, and Emmanuel Saez (2002), "Participation and Investment Decisions in a Retirement Plan: The Influence of Colleagues' Choices," Journal of Public Economics 85, 121148.

— (2003), "The Role of Information and Social Interactions in Retirement Plan Decisions: Evidence from a Randomized Experiment," The Quarterly Journal of Economics $118,815-842$.

Ehrlich, Isaac, and Hiroyuki Chuma (1990), "A Model of the Demand for Longevity and the Value of Life Extension," Journal of Political Economy 98, 761-782.

Espeland, M.A., S.R. Rapp, S.A. Shumaker, R. Brunner, J.E. Manson, B.B. Sherwin, J. Hsia, K.L. Margolis, P.E. Hogan, R. Wallace, M. Dailey, R. Freeman, and J. Hays (2004), "Conjugated Equine Estrogens and Global Cognitive Function in Postmenopausal Women," Journal of the American Medical Association 291, 2959-2968.

Espinosa, Javier, and William N. Evans (2008), "Heightened Mortality After the Death of a Spouse: Marriage Protection or Marriage Selection?" Journal of Health Economics 27, 13261342.

Falba, Tracy A., and Jody L. Sindelar (2008), "Spousal Concordance in Health Behavior Change," Health Services Research 43, 96 - 116.

Fletcher, Jason (2009), "All in the Family: Mental Health Spillover Effects between Working Spouses," The B.E. Journal of Economic Analysis 86 Policy 9, Article 3.

Fletcher, Jason M. (2007), "Social Multipliers In Sexual Initiation Decisions Among U.S. High School Students," Demography 44, 373388. 
Food and Drug Administration (2002), "Women's Health Initiative (WHI) Results Signal Need for Reassessment of Risks and Benefits of Conjugated Equine Estrogens/Medroxyprogesterone Acetate (Prempro) in Postmenopausal Women," FDA Satement, 13 August 2002.

- (2009), "Menopause \& Hormones," Available at http://www.fda.gov/downloads/ ForConsumers/ByAudience/ForWomen/FreePublications/UCM127435.pdf.

Gaviria, Alejandro, and Steven Raphael (2001), "School-Based Peer Effects and Juvenile Behavior," The Review of Economics and Statistics 83, 257268.

Glanz, Karen, Barbara K. Rimer, and K. Viswanath (2008), Health Behavior and Health Education: Theory, Research and Practice, Jossey-Bass.

Grossman, Michael (1972), "On the Concept of Health Capital and the Demand for Health," Journal of Political Economy 80, 225-255.

Hemminki, Elina, Dianne L. Kennedy, Carlene Baum, and Sonja M. Mckinlay (1988), "Prescribing of Noncontraceptive Estrogens and Progestins in the United States, 1974-86," American Journal of Public Health 78, 1479-1481.

Hersh, Adam L., Marcia L. Stefanick, and Randall S. Stafford (2004), "National Use of Postmenopausal Hormone Therapy," Journal of the Medical Association 291, 47-53.

Hulley, S., D. Grady, T. Bush, C. Furberg, D. Herrington, B. Riggs, and E. Vittinghoff (1998), "Randomized Trial of Estrogen Plus Progestin for Secondary Prevention of Coronary Heart Disease in Postmenopausal Women," The Journal of the American Medical Association 280, 605-613.

Iizuka, Toshiaki, and Ginger Zhe Jin (2005), "The Effect of Prescription Drug Advertising on Doctor Visits," Journal of Economics \&3 Management Strategy 14, 701-727.

_ (forthcoming), "Drug Advertising and Health Habit," Applied Microeconomics, Volume Communication Games .

Jones, T., M. Fowler, and D. Hubbard (2000), "Refining a tool to measure cues to action in encouraging health-promoting behavior - The CHAQ," American Journal of Health Promotion 14, 170-173.

Kahn, Matthew E. (1999), "Diabetic Risk Taking: The Role of Information, Education and Medication," Journal of Risk and Uncertainty 18, 147-164.

Kremer, Michael (1996), "Integrating Behavioral Choice into Epidemiological Models of AIDS," Quarterly Journal of Economics 61, 549-573. 
Kremer, Michael, and Dan Levy (2008), "Peer Effects and Alcohol Use among College Students," Journal of Economic Perspectives 22, 189206.

Laibson, David (1997), "Golden Eggs and Hyperbolic Discounting," The Quarterly Journal of Economics 112, 443-477.

Leonard, Kenneth E., and Pamela Mudar (2004), "Husbands' Influence on Wives' Drinking: Testing a Relationship Motivation Model in the Early Years of Marriage," Psychology of Addictive Behaviors 18, 340349.

Lindgren, Bjorn, and Charles Stuart (1980), "The Effects of Traffic Safety Regulation in Sweden," Journal of Political Economy 88, 412-427.

Ling, Dania C., Ernst R. Berndt, and Magaret K. Kyle (2002), "Deregulating direct-toconsumer marketing of prescription drugs: Effects on prescription and over-the-counter product sales." Journal of Law and Economics 45, 691-723.

Loewenstein, George, Troyen Brennan, and Kevin G. Volpp (2007), "Asymmetric Paternalism to Improve Health Behaviors," The Journal of the American Medical Association 298, $2415-2417$.

Lundborg, Petter (2006), "Having the Wrong Friends? Peer Effects in Adolescent Substance Use," Journal of Health Economics 25, 214233.

McKee, J. (1994), "Cues to action in prostate cancer screening," Oncol Nurs Forum 21, $1171-1176$.

Mckinlay, Sonja M. (1996), "The Normal Menopause Transition: An Overview," Maturitas $23,137-145$.

Mckinlay, Sonja M., Donald J. Brambilla, and Jennifer G. Posner (2008), "The Normal Menopause Transition," Maturitas 61, 4-16.

National Heart, Lung and Blood Institute (2005), "Facts About Menopause Hormone Therapy," NIH Publication No. 05-5200.

Newton, K.M., A.Z. LaCroix, D.S.M. Buist, L.A. Anderson, and K. Delaney (2001), "What Factors Account for Hormone Replacement Therapy Prescribing Frequency?" Maturitas 39, 1-10.

Olsen, Sara, Simon Smith, Tian P.S. Oei, and James Douglas (2010), "Cues to Starting CPAP in Obstructive Sleep Apnea: Development and Validation of the Cues to CPAP Use Questionnaire," Journal of Clinical Sleep Medicine 6, 229-237. 
Parkinson, Kristy, Joseph Price, Kosali Simon, and Sharon Tennyson (2008), "The Influence of FDA Advisory Information and Black Box Warnings on Consumer Use of Prescription Antidepressants," SSRN Working Paper.

Peltzman, Sam (1975), "The Effects of Automobile Safety Regulation The Effects of Automobile Safety Regulation," The Journal of Political Economy 83, 677-726. - (2002), "Offsetting Behavior and Medical Breakthroughs," Working Paper.

Powell, Lisa M., John A. Tauras, and Hana Ross (2005), "The Importance of Peer Effects, Cigarette Prices and Tobacco Control Policies for Youth Smoking Behavior," Journal of Health Economics 24, 950968.

Rapp, S.R., M.A. Espeland, S.A. Shumaker, V.W. Henderson, R.L. Brunner, J.E. Manson, M.L. S. Gass, M.L. Stefanick, D.S. Lane, J.Hays, K.C. Johnson, L.H. Coker, M. Dailey, and D. Bowen (2003), "Effect of Estrogen Plus Progestin on Global Cognitive Function in Postmenopausal Women," Journal of the American Medical Association 289, 2663-2672.

Rolnick, S.J., R.A. Kopher, R.B. Compo, M.E. Kelley, and T.A. DeFor (1999), "Provider Attitudes and Self-Reported Behaviors Related to Hormone Replacement Therapy," Menopause 6, 257-263.

Rossouw, Jacques E. (1996), "Estrogens for Prevention of Coronary Heart Disease: Putting the Brakes on the Bandwagon," Circulation 94, 2982-2985.

Schultz, Theodore W. (1975), "The Value of the Ability to Deal with Disequilibria," Journal of Economic Literature 13, 827-846.

Shumaker, S.A., C. Legault, L. Kuller, S.R. Rapp, L. Thal, D.S. Lane, H. Fillit, M.L. Stefanick, S.L. Hendrix, C.E. Lewis, K. Masaki, and L.H. Coker (2004), "Conjugated Equine Estrogens and Incidence of Probable Dementia and Mild Cognitive Impairment in Postmenopausal Women," Journal of the American Medical Association 291, 2947-2958.

Shumaker, S.A., C. Legault, S.R. Rapp, L. Thal, R.B. Wallace, J.K. Ockene, S.L. Hendrix, B.N. Jones III, A.R. Assaf, R.D. Jackson, J. Morley Kotchen, S. Wassertheil-Smoller, and Jean Wactawski-Wende (2003), "Estrogen Plus Progestin and the Incidence of Dementia and Mild Cognitive Impairment in Postmenopausal Women," Journal of the American Medical Association 289, 2651-2662.

Smith, Kirsten P., and Nicholas A. Christakis (2008), "Social Networks and Health," The Annual Review of Sociology 34, 40529.

The American Heart Association (1997), "Guide to Primary Prevention of Cardiovascular Diseases," Circulation 95, 2329-2331. 
_ (1999), "Guide to Preventive Cardiology for Women," Circulation 99, 2480-2484.

_ (2002), "AHA Guidelines for Primary Prevention of Cardiovascular Disease and Stroke: 2002 Update," Circulation 106, 388-391.

_ (2007), "Evidence-Based Guidelines for Cardiovascular Disease Prevention in Women: 2007 Update," Circulation 115, 1481-1501.

The North American Menopause Society (2006), Menopause Guidebook.

Viscusi, Kip (1985), "Consumer Behavior and the Safety Effects of Product Safety Regulation," Journal of Law and Economics 28, 527-553.

Viscusi, W. Kip (1984), "The Lulling Effect: The Impact of Child-Resistant Packaging on Aspirin and Analgesic Ingestions," American Economic Review 54, 324-327.

Watkins, Elizabeth Siegel (2007), The Estrogen Elixir, The Johns Hopkins University Press.

Wosinska, Marta (2005), "Direct-to-Consumer Advertising and Drug Therapy Compliance," Journal of Marketing Research 42, 323-332.

Writing Group for the Womens Health Initiative Investigators (2002), "Risks and Benefits of Estrogen Plus Progestin in Healthy Postmenopausal Women," Journal of the American Medical Association 288, 321-333.

Wu, Stephen (2005), "Fatalistic Tendencies: An Explanation of Why People Don’t Save," Contributions to Economic Analysis and Policy 4, Article 11.

Wysowski, Diane K., Linda Golden, and Laurie Burke (1995), "Use of Menopausal Estrogens and Medroxyprogesterone in the United States, 1982-1992," Obstetrics and Gynecology 85, $6-10$. 


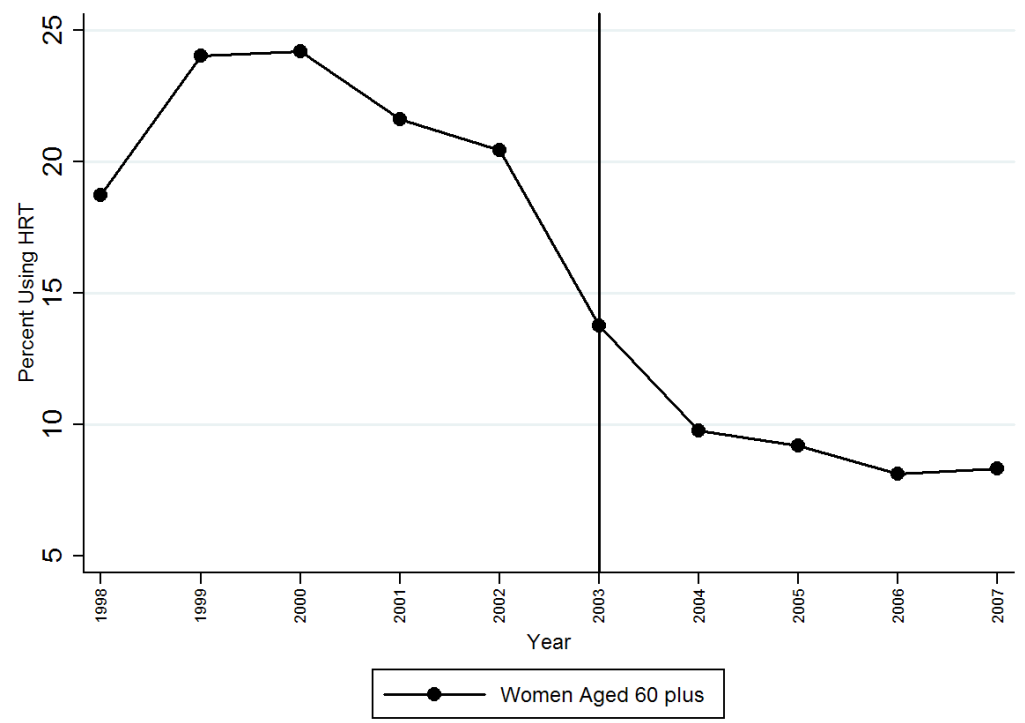

(a) HRT Use Among Women: Medical Expenditure Panel Survey, 1997-2007

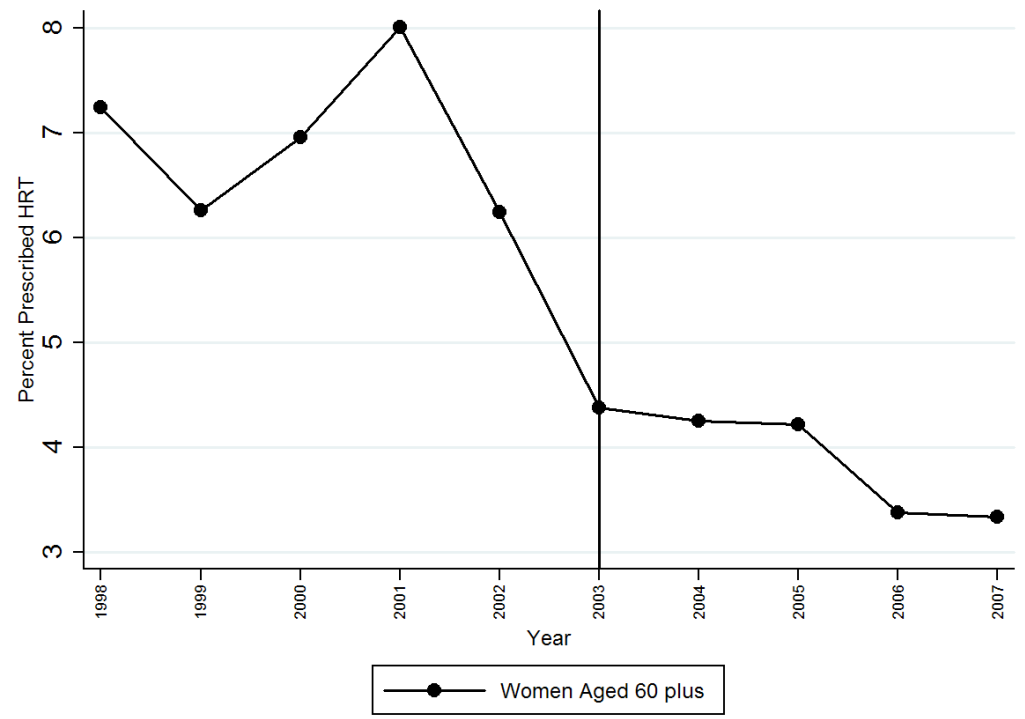

(b) HRT Prescriptions Among Office Visits: National Ambulatory Medical Care Survey, 1997-2007

Figure 1: Prevalence of HRT Among Post-Menopausal Women 


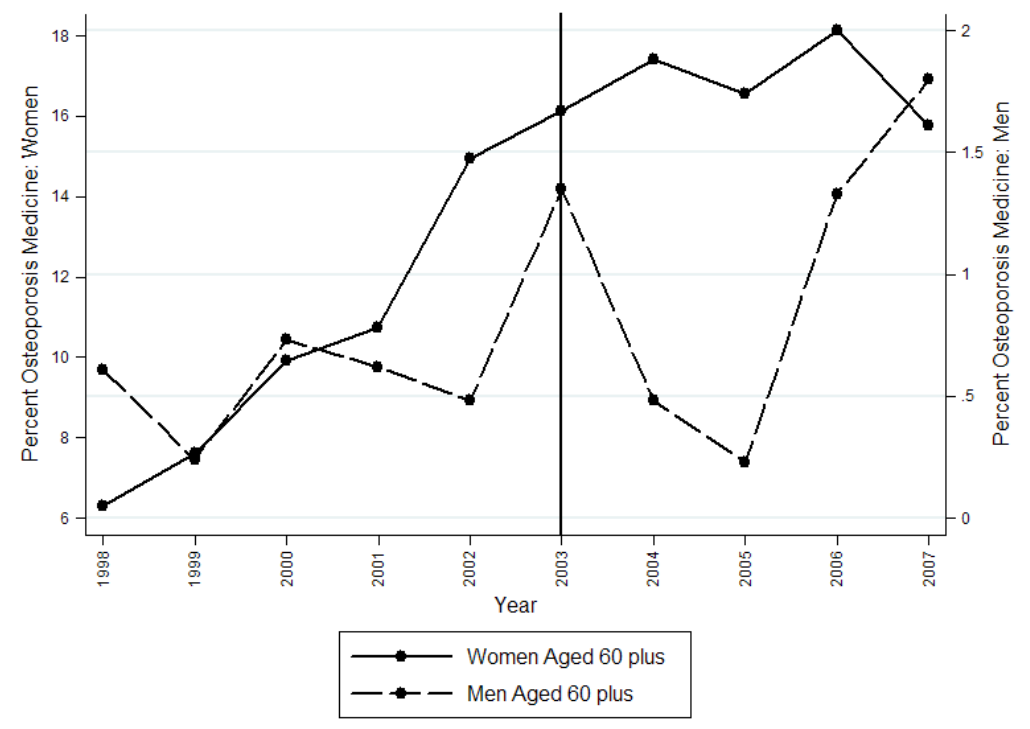

(a) Use of Alternative Osteoporosis Medicine: Medical Expenditure Panel Survey, 1997-2007

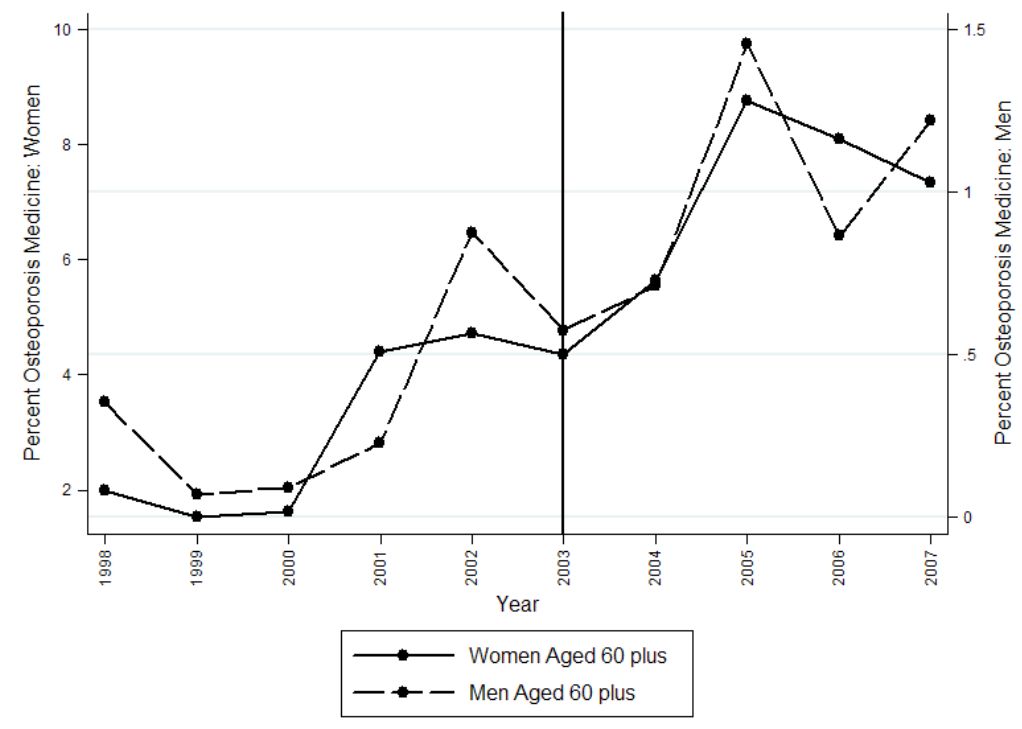

(b) Alternative Osteoporosis Medication Prescriptions Among Office Visits: National Ambulatory Medical Care Survey, 1997-2007

Figure 2: Use of Alternative Osteoporosis Medications 


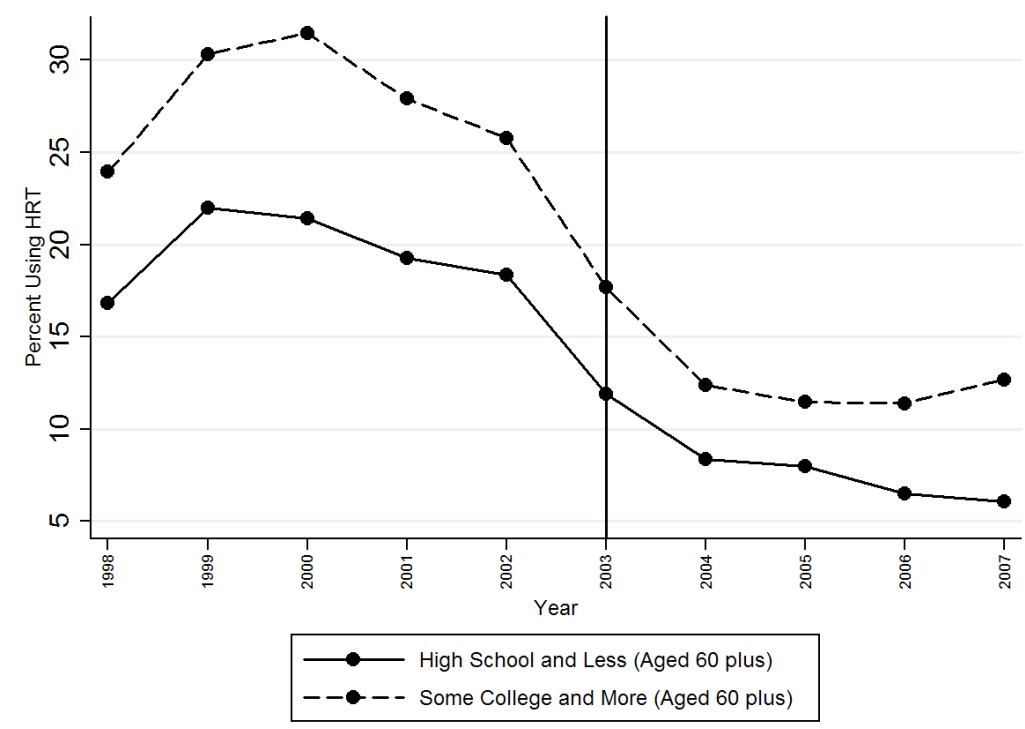

Figure 3: Prevalence of HRT Among Post-Menopausal Women by Education: Medical Expenditure Panel Survey, 1997-2007 
Table 1: Summary Statistics for Outcome Variables: BRFSS Data, 1998-2007

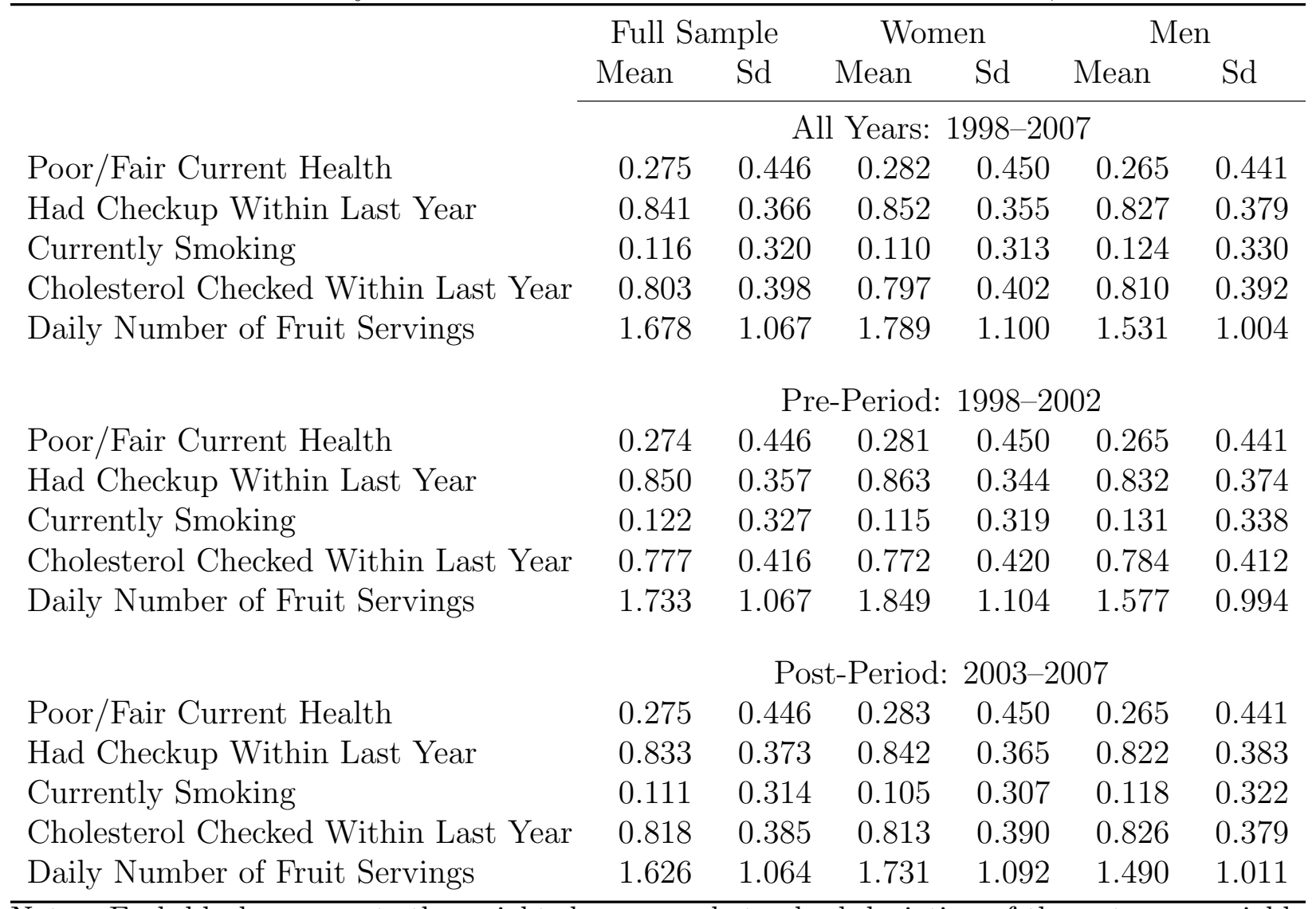

Notes: Each block represents the weighted mean and standard deviation of the outcome variable in a separate group based on indicators of treatment status (full sample/females/males) and treatment period (all years/pre-treatment period/post-treatment period). Weighting is based on finalwt variable from the BRFSS. 
Table 2: Summary Statistics for Control Variables: BRFSS Data, 1998-2007

\begin{tabular}{lcccccc}
\hline & \multicolumn{2}{c}{ Full Sample } & \multicolumn{2}{c}{ Women } & \multicolumn{2}{c}{ Men } \\
& Mean & Sd & Mean & Sd & Mean & Sd \\
\cline { 2 - 6 } Age & 70.991 & 7.792 & 71.573 & 7.946 & 70.219 & 7.513 \\
Non-Hispanic White & 0.822 & 0.382 & 0.822 & 0.383 & 0.823 & 0.382 \\
Non-Hispanic Black & 0.077 & 0.266 & 0.082 & 0.274 & 0.070 & 0.255 \\
Non-Hispanic Other & 0.039 & 0.194 & 0.035 & 0.184 & 0.045 & 0.206 \\
Hispanic & 0.062 & 0.241 & 0.061 & 0.240 & 0.063 & 0.243 \\
Less than High School & 0.180 & 0.384 & 0.188 & 0.391 & 0.169 & 0.374 \\
High School & 0.344 & 0.475 & 0.381 & 0.486 & 0.295 & 0.456 \\
Some College & 0.228 & 0.419 & 0.239 & 0.427 & 0.213 & 0.409 \\
College and More & 0.248 & 0.432 & 0.192 & 0.394 & 0.323 & 0.468 \\
Married & 0.607 & 0.488 & 0.492 & 0.500 & 0.761 & 0.427 \\
Single & 0.359 & 0.480 & 0.475 & 0.499 & 0.206 & 0.404 \\
Never Married & 0.033 & 0.179 & 0.033 & 0.179 & 0.033 & 0.180 \\
Less than $\$ 20,000$ & 0.283 & 0.451 & 0.353 & 0.478 & 0.204 & 0.403 \\
[\$20,000, $\$ 25,000)$ & 0.135 & 0.342 & 0.145 & 0.352 & 0.124 & 0.330 \\
[\$25,000, $\$ 35,000)$ & 0.173 & 0.379 & 0.173 & 0.379 & 0.173 & 0.378 \\
[35,000, \$50,000) & 0.162 & 0.369 & 0.147 & 0.354 & 0.180 & 0.384 \\
$\$ 50,000$ and More & 0.246 & 0.431 & 0.182 & 0.386 & 0.319 & 0.466 \\
Insured & 0.954 & 0.210 & 0.956 & 0.206 & 0.951 & 0.215 \\
\hline Notes: Eahyyyyyyy
\end{tabular}

Notes: Each cell represents the weighted mean and standard deviation of the variable in a separate group based on indicators of treatment status (full sample/females/males). Weighting is based on finalwt variable from the BRFSS. 
Table 3: Effects of the WHIS Results on Health and Health Behavior

\begin{tabular}{|c|c|c|c|}
\hline & $\begin{array}{l}\text { Pre-period mean } \\
\text { of the outcome } \\
\text { among women } \\
(1)\end{array}$ & $\begin{array}{l}\text { Simple DID } \\
(2)\end{array}$ & $\begin{array}{c}\text { DID } \\
(3)\end{array}$ \\
\hline $\begin{array}{l}\text { Poor/Fair Current Health } \\
(\mathrm{N}=616913)\end{array}$ & 0.281 & $\begin{array}{c}0.001 \\
(0.002)\end{array}$ & $\begin{array}{r}-0.001 \\
(0.003) \\
{[0.409]}\end{array}$ \\
\hline $\begin{array}{l}\text { Checkup Within Last Year } \\
(\mathrm{N}=400499)\end{array}$ & 0.863 & $\begin{array}{r}-0.007^{*} \\
(0.004)\end{array}$ & $\begin{array}{r}-0.007^{*} \\
(0.004) \\
{[0.671]}\end{array}$ \\
\hline $\begin{array}{l}\text { Currently Smoking } \\
(\mathrm{N}=617396)\end{array}$ & 0.115 & $\begin{array}{c}0.003 \\
(0.003)\end{array}$ & $\begin{array}{c}0.004 \\
(0.003) \\
{[0.236]}\end{array}$ \\
\hline $\begin{array}{l}\text { Cholesterol Checked Within Last Year } \\
(\mathrm{N}=334671)\end{array}$ & 0.772 & $\begin{array}{r}-0.001 \\
(0.007)\end{array}$ & $\begin{array}{r}-0.003 \\
(0.007) \\
{[0.479]}\end{array}$ \\
\hline $\begin{array}{l}\text { Daily Number of Fruit Servings } \\
(\mathrm{N}=366410)\end{array}$ & 1.849 & $\begin{array}{r}-0.022^{*} \\
(0.012)\end{array}$ & $\begin{array}{r}-0.023^{*} \\
(0.012) \\
{[0.797]}\end{array}$ \\
\hline
\end{tabular}

Notes: Each row provides results on a separate outcome variable. The first column provides means of the outcome variables among women during the pre-treatment period. Columns (2)-(3) provide the effects of the medical information provided by the WHIS on health and health related behavior. Covariates in column (3) include complete set of dummies for age, race, marital status, income, insurance status, month and year of survey, and state of residence. Regressions are weighted by the final weights (finalwt) provided in the BRFSS. Robust standard errors clustered at the state level are shown in parenthesis below coefficients. Column (3) also provides in square brackets the P-value corresponding to a test of the equality of the pre-treatment trends in outcomes between men and women. ${ }^{*} p<0.10,{ }^{* *} p<0.05,{ }^{* * *} p<0.01$. 


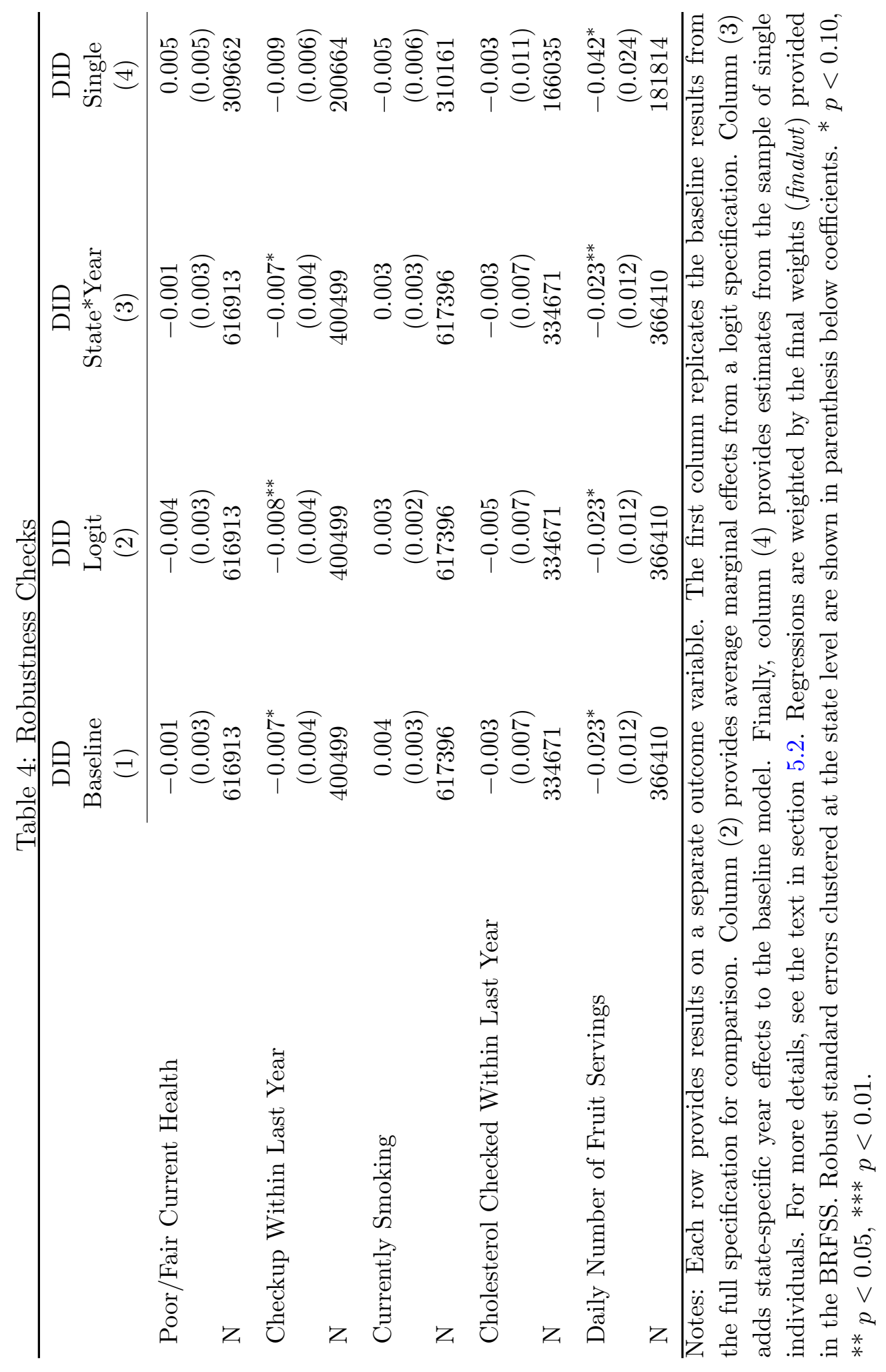


Table 5: Heterogeneous Effects by Education

\begin{tabular}{|c|c|c|c|}
\hline & $\begin{array}{c}\text { Full Sample } \\
\text { (1) }\end{array}$ & $\begin{array}{l}\text { High School } \\
\text { or Less } \\
(2)\end{array}$ & $\begin{array}{c}\text { Some College } \\
\text { and More } \\
(3)\end{array}$ \\
\hline Poor/Fair Current Health & $\begin{array}{c}-0.001 \\
(0.003) \\
{[0.281]}\end{array}$ & $\begin{array}{c}0.008 \\
(0.008) \\
{[0.343]}\end{array}$ & $\begin{array}{c}-0.010 \\
(0.008) \\
{[0.189]}\end{array}$ \\
\hline $\mathrm{N}$ & 616913 & 311640 & 305273 \\
\hline Checkup Within Last Year & $\begin{array}{r}-0.007^{*} \\
(0.004) \\
{[0.863]}\end{array}$ & $\begin{array}{r}-0.013^{*} \\
(0.007) \\
{[0.862]}\end{array}$ & $\begin{array}{c}0.001 \\
(0.007) \\
{[0.864]}\end{array}$ \\
\hline $\mathrm{N}$ & 400499 & 199663 & 200836 \\
\hline Currently Smoking & $\begin{array}{c}0.004 \\
(0.003) \\
{[0.115]}\end{array}$ & $\begin{array}{c}0.004 \\
(0.004) \\
{[0.127]}\end{array}$ & $\begin{array}{c}0.002 \\
(0.002) \\
{[0.097]}\end{array}$ \\
\hline $\mathrm{N}$ & 617396 & 312207 & 305189 \\
\hline Cholesterol Checked Within Last Year & $\begin{array}{c}-0.003 \\
(0.007) \\
{[0.772]}\end{array}$ & $\begin{array}{c}-0.008 \\
(0.007) \\
{[0.758]}\end{array}$ & $\begin{array}{c}-0.000 \\
(0.010) \\
{[0.794]}\end{array}$ \\
\hline $\mathrm{N}$ & 334671 & 165921 & 168750 \\
\hline Daily Number of Fruit Servings & $\begin{array}{r}-0.023^{*} \\
(0.012) \\
{[1.849]}\end{array}$ & $\begin{array}{c}-0.047^{* * *} \\
(0.012) \\
{[1.758]}\end{array}$ & $\begin{array}{c}-0.009 \\
(0.021) \\
{[1.984]}\end{array}$ \\
\hline $\mathrm{N}$ & 366410 & 182732 & 183678 \\
\hline
\end{tabular}

Notes: Each row provides results on a separate outcome variable. The first column replicates the baseline results from the full specification for comparison. Column (2) provides estimates from the sample of individuals with a high school degree or less, whereas column (3) provides estimates for those with at least some college education. Regressions are weighted by the final weights (finalwt) provided in the BRFSS. Robust standard errors clustered at the state level are shown in parenthesis below coefficients. Pre-period means of the outcome variables are provided in square brackets for each group of women. ${ }^{*} p<0.10,{ }^{* *} p<0.05,{ }^{* * *}$ $p<0.01$. 


\section{Appendix}

Since the BRFSS does not contain information on the use of prescription medication, we employ additional data from the Medical Expenditure Panel Survey (MEPS) and the National Ambulatory Medical Care Survey (NAMCS) to document changes in HRT use as well as changes in the utilization of other osteoporosis medications. ${ }^{36}$ The household component of MEPS includes data from a nationally representative sample of the U.S. civilian noninstitutionalized population. Respondents are interviewed about their medical expenditures and utilization of medical services over a period of two years through five interview rounds. Part of the household component (the prescribed medicine file) provides information on the prescription medicines purchased by the respondent in each round along with the three digit ICD-9 codes denoting the medical conditions for which the prescription medicine was purchased. We supplement the MEPS household component data with additional information from the Physician's Desk Reference Companion Guide (PDRCG), an annual publication on prescription drugs available on the market. The Physician's Desk Reference Companion is regarded as one of the most respected and used handbooks by physicians to select medications for their patients (Watkins, 2007). We use the "Therapeutic Indications Index", a list of medications and the conditions for which they are indicated, to identify the HRT drugs that were available during our analysis period. Trade-name drugs that contain hormones to treat menopause and their generic substitutes are listed under the label "Menopause, Vasomotor Symptoms of". We classify an individual as using HRT if the person reports purchasing at least one HRT product at any time during the round.

NAMCS is a national survey on the use of ambulatory medical care services in the U.S. The unit of observation in the data is a physician-patient visit based on a random sample of visits to non-federally employed physicians. ${ }^{37}$ It provides information on the patient's demographic characteristics and symptoms, the physician's diagnoses, the prescribed medications associated with the visit as well as the therapeutic class of the medications. The therapeutic class of drugs is based on the National Drug Code Directory for the period 1998-2005 and its successor the Lexicon Plus, a proprietary database of Cerner Multum, Inc. for the period 2006-2007. The public data files provide information on up to six medications for 1998-2003 and eight medications for 2004-2007. They also provide one therapeutic class for each medication for 1998-2001, three therapeutic classes for 2001-2005 and four therapeutic

\footnotetext{
${ }^{36}$ As discussed in the introduction, HRT was the only recommended pharmacological intervention for the primary prevention of cardiovascular disease. After the WHIS results, the published guidelines emphasized adoption of healthy life habits as the leading strategy in the prevention of heart disease. For that reason, we only examine changes in alternative osteoporosis medicines.

${ }^{37}$ The data excludes visits to physicians in the specialties of anesthesiology, pathology, and radiology. It also excludes telephone consults, visits that occur outside the physician's office, including the hospital (provided that the physician does not have a private office there) and other institutions that are primarily responsible for the patients's care (e.g. nursing homes), and visits with only administrative purposes (e.g. filling forms).
} 
classes for 2006-2007. In cases when there are multiple therapeutic class codes, we use the primary code associated with the medication. We classify a visit as resulting with an HRT prescription if any of the listed medications has a (primary) National Drug Code of "1034 Estrogens/Progestins" or Multum code of "183 Estrogens" or "185 Progestins".

The National Osteoporosis Foundation provides the list of medications that are FDAapproved for the prevention or treatment of osteoporosis along with their approval date (see Table A1). We use the provided information to examine changes in the utilization of alternative osteoporosis drugs. We classify an individual in MEPS as using an alternative osteoporosis medication if the person reports purchasing at least one of these listed products at any time during the round. Similarly, we classify an office visit in NAMCS as resulting with an alternative osteoporosis prescription if the list of medications in the data includes any of these osteoporosis drugs. 
Table A1: Alternative Osteoporosis Medicines

\begin{tabular}{lc}
\hline \multicolumn{1}{c}{\begin{tabular}{c} 
Drug Name \\
\multicolumn{1}{c}{$(1)$}
\end{tabular}} & $\begin{array}{c}\text { FDA Approval Year } \\
(2)\end{array}$ \\
\hline Alendronate & 1995 \\
Fosamax & 1995 \\
Fosamax Plus D & 1995 \\
Calcitonin & 1995 \\
Fortical & 1995 \\
Miacalcin & 1995 \\
Raloxifene & 1997 \\
Evista & 1997 \\
Risendronate & 2000 \\
Actonel & 2000 \\
Actonel with Calcium & 2000 \\
Atelvia & 2000 \\
Teriparatide & 2002 \\
Forteo & 2002 \\
Ibandronate & 2005 \\
Boniva & 2005 \\
Zoledronic Acid & 2007 \\
Reclast & 2007 \\
Denosumab & 2010 \\
Prolia TM & 2010 \\
\hline
\end{tabular}

Source: The National Osteoporosis Foundation. Available at http://www.nof.org/ aboutosteoporosis/managingandtreating/medicinesneedtoknow, accessed on August 10, 2011. Note: Column (1) includes both brand and generic drug names. 